\title{
Snake Venom Prothrombin Activators Homologous to Blood Coagulation Factor Xa
}

\author{
Jeremiah S. Josepha,d R. Manjunatha Kini ${ }^{\mathrm{b}, \mathrm{c}}$ \\ aDepartment of Biochemistry, Faculty of Medicine, ${ }^{b}$ Department of Biological Sciences, \\ Faculty of Science, National University of Singapore, Singapore; \\ 'Department of Biochemistry and Molecular Biophysics, Medical College of Virginia, \\ Virginia Commonwealth University, Richmond, Va., USA; dBioinformatics Centre, \\ Institute of Molecular and Cell Biology, Singapore
}

\section{Key Words}

Snake venom - Procoagulants .

Prothrombin activators · Factor $\mathrm{Xa}$

\begin{abstract}
We have recently determined the complete amino acid sequence of trocarin, a group $D$ prothrombin activator from the venom of Tropidechis carinatus (Australian roughscaled snake). This proteinase is both functionally and structurally similar to mammalian blood coagulation factor $\mathrm{Xa}$. It shows $\sim 70 \%$ homology and possesses the characteristic Gla domain, two EGF domains and serine proteinase domain. To examine structure-function relationships, we generated a molecular model of trocarin based on a human factor $\mathrm{Xa}$ des-Gla crystal structure (1xka) as template. Based on known sites of interaction between mammalian factor $\mathrm{Xa}$,
\end{abstract}

factor $\mathrm{Va}$ and prothrombin, structure-function relationships of trocarin were explored. Unlike factor $\mathrm{Xa}$, trocarin is glycosylated and has a large carbohydrate moiety at the entrance to its active site pocket. This might contribute to differences observed in the kinetics of hydrolysis of synthetic substrates by trocarin as compared to human factor Xa. A $\mathrm{Ca}^{2+}$-binding loop present in the heavy chain of factor Xa also seems to be lost in trocarin. In addition to its role in hemostasis, factor Xa shows other biological effects, including inflammation via its interaction with effector protease receptor-1 (EPR-1). Interestingly, the EPR-1 recognition site is distinctly different in trocarin, the functional consequences of which are being investigated.

Copyright $@ 2002$ S. Karger AG, Basel

\begin{tabular}{ll}
\hline KARGER & ( ) 2002 S. Karger AG, Basel \\
$\begin{array}{l}\text { Fax +4161306 1234 } 301-0147 / 01 / 0316-0234 \$ 17.50 / 0 \\
\begin{array}{l}\text { E-Mail karger@karger.ch } \\
\text { www.karger.com }\end{array}\end{array}$ & $\begin{array}{l}\text { Accessible online at: } \\
\text { www.karger.com/journals/hae }\end{array}$
\end{tabular}

\footnotetext{
R. Manjunatha Kini

Department of Biological Sciences, Faculty of Science

Block S2, Room 04-11, 14 Science Drive

National University of Singapore, Singapore 117543

Tel. +65 874 5235, Fax +65 779 2486, E-Mail dbskinim@nus.edu.sg
} 


\section{Introduction}

The activation of prothrombin to thrombin is accomplished in vivo by the prothrombinase complex, consisting of a serine proteinase factor $\mathrm{Xa}$, and a cofactor factor Va, assembled on negatively charged phospholipid membranes in the presence of $\mathrm{Ca}^{2+}$ ions [1]. Various exogenous hemostatic factors have also been isolated that specifically act on prothrombin [2]. Snake venom is a rich source of prothrombin-activating proteinases [2-4]. Based on cofactor requirements in prothrombin activation, these venom proteinases have been classified into four groups: Groups A, B, $\mathrm{C}$ and D [5]. Group A activators (example, ecarin, Echis carinatus) are metalloproteinases that require no cofactors and efficiently convert prothrombin into meizothrombin [6]. Group B activators are metalloproteinases C-type lectin complexes (example, carinactivase-1, Echis carinatus) that also convert prothrombin to meizothrombin, but require $\mathrm{Ca}^{2+}$ ions for activity [7]. Group C prothrombin activators (example, pseutarin, Pseudonaja textilis) are large multi-subunit proteinases that activate prothrombin to mature thrombin, cleaving both the necessary peptide bonds [8]. Prothrombin conversion by these proteins is greatly enhanced by $\mathrm{Ca}^{2+}$ ions and phospholipids. Group D activators (example, trocarin, Tropidechis carinatus) are found exclusively in Australian elapids [9]. They also convert prothrombin to mature thrombin, a reaction greatly enhanced by blood coagulation factor $\mathrm{Va}$, negatively charged phospholipids and $\mathrm{Ca}^{2+}$ ions. In this respect, group D prothrombin activators strongly resemble blood coagulation factor Xa.

Structural characterization of these proteinases was expected to contribute significantly towards understanding structure-function relationships and mechanisms of factor Xa-mediated prothrombin activation. More- over, the phylogenetic distance and functional similarities between these proteinases and factor Xa would help define molecular details of interactions among the protein components of the prothrombinase complex. Therefore, we initiated studies on trocarin, the group $\mathrm{D}$ prothrombin activator from the venoms of the Australian rough-scaled snake, T. carinatus.

\section{Functional Characterization}

Trocarin was purified from crude venom by reversed-phase HPLC [9]. It has similar dose-dependent procoagulant effects to human factor Xa on human plasma [9]. Similar to factor $\mathrm{Xa}$, it cleaves prothrombin at both peptide bonds, $\operatorname{Arg}_{274}-\mathrm{Thr}_{275}$ and $\operatorname{Arg}_{323}-$ $\mathrm{Ile}_{324}$, required to convert it to mature thrombin [9]. Characteristic of group D activators, its prothrombin-converting activity is greatly enhanced by factor $\mathrm{Va}, \mathrm{Ca}^{2+}$ ions and phospholipids [9]. Though the activity of the entire complex is comparable to that of the mammalian prothrombinase complex, trocarin has a higher basal activity in the absence of all cofactors compared to bovine and human factor Xa. Hence the stimulation of trocarin by the cofactors is generally $\sim 10$-fold lower than that of bovine and human factor Xa [9]. Trocarin cleaves the factor Xa-specific chromogenic substrates S-2222 and S-2765. Interestingly, while the $\mathrm{K}_{\mathrm{m}} \mathrm{s}$ of trocarin and factor $\mathrm{Xa}$ are comparable, the $\mathrm{V}_{\max }$ for trocarin is about $\sim 1,000$-fold lower than that of mammalian factor Xa. This indicates that while the affinity of the enzymes for the peptide substrate is very similar, product release is likely impaired only in the venom enzyme. Similar low amidolytic activity was also reported for notecarin (Notechis scutatus scutatus) [10]. Finally, trocarin was lethal to mice at $1 \mathrm{mg} / \mathrm{kg}$ body weight i.p., likely causing disseminated intra- 


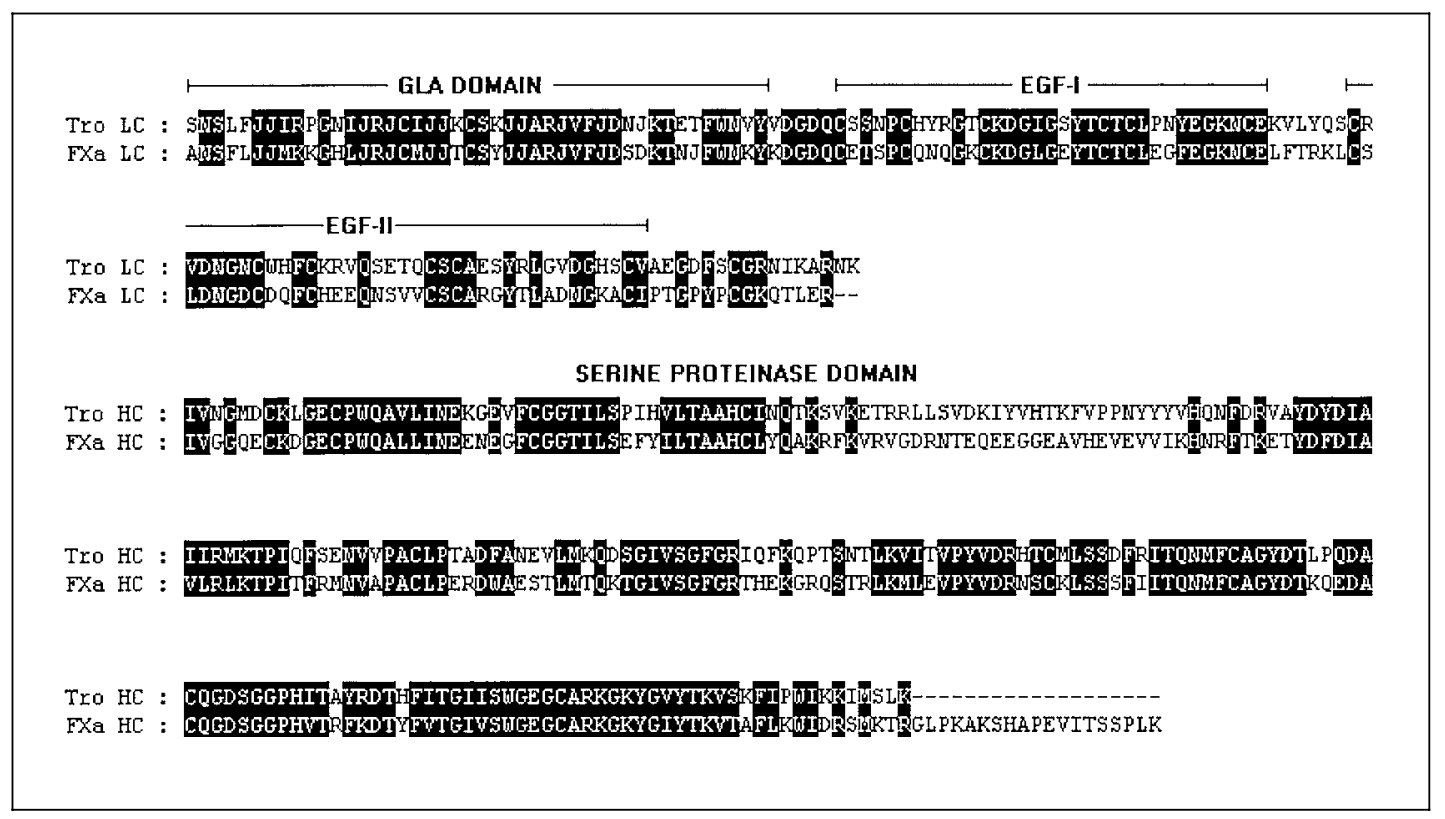

Fig. 1. Alignment of amino acid sequence of trocarin (SWISS-PROT \#P81428) with human factor Xa sequence (\#P00742). Identical residues are shaded. Gla, EGF-I, EGF-II and serine proteinase domain boundaries are indicated above light chain sequences. $\mathrm{J}=$ Gla residue.

vascular coagulopathy and is therefore expected to play the role of a toxin [9]. Hence a novel function has been ascribed to factor $\mathrm{Xa}$, in addition to its well-known roles in coagulation, inflammation [for example, see ref. 11] and mitogenesis [for example, see ref. 12, 13].

\section{Amino Acid Sequencing and Determination of Posttranslational Modifications}

To ascertain its molecular identity, the Nterminal sequence of trocarin was determined. The protein consists of a light and a heavy chain; their $\mathrm{N}$-terminal sequences have high homology to the corresponding chains of factor Xa. The complete amino acid sequence of trocarin was subsequently determined (fig. 1) [9]. Trocarin has 141 residues in its light chain and 235 residues in its heavy chain. All Cys residues have the same positions as those in factor Xa. Thus, based on sequence homology, trocarin has a domain structure identical to that of factor $\mathrm{Xa}$ (fig. 1, 2). The light chain consists of an N-terminal Gla domain (see below), followed by two EGF-like domains. The heavy chain is the serine proteinase catalytic domain (fig. 2).

During sequencing, several posttranslational modifications were observed. Eleven Gla residues in the N-terminal portion of their light chains were identified by mass spectrometry and resequencing the decarboxylated light chain. Comparison of trocarin and factor Xa sequences suggest that Gla residues in positions $6,7,14,16,19,20,25,26$, 


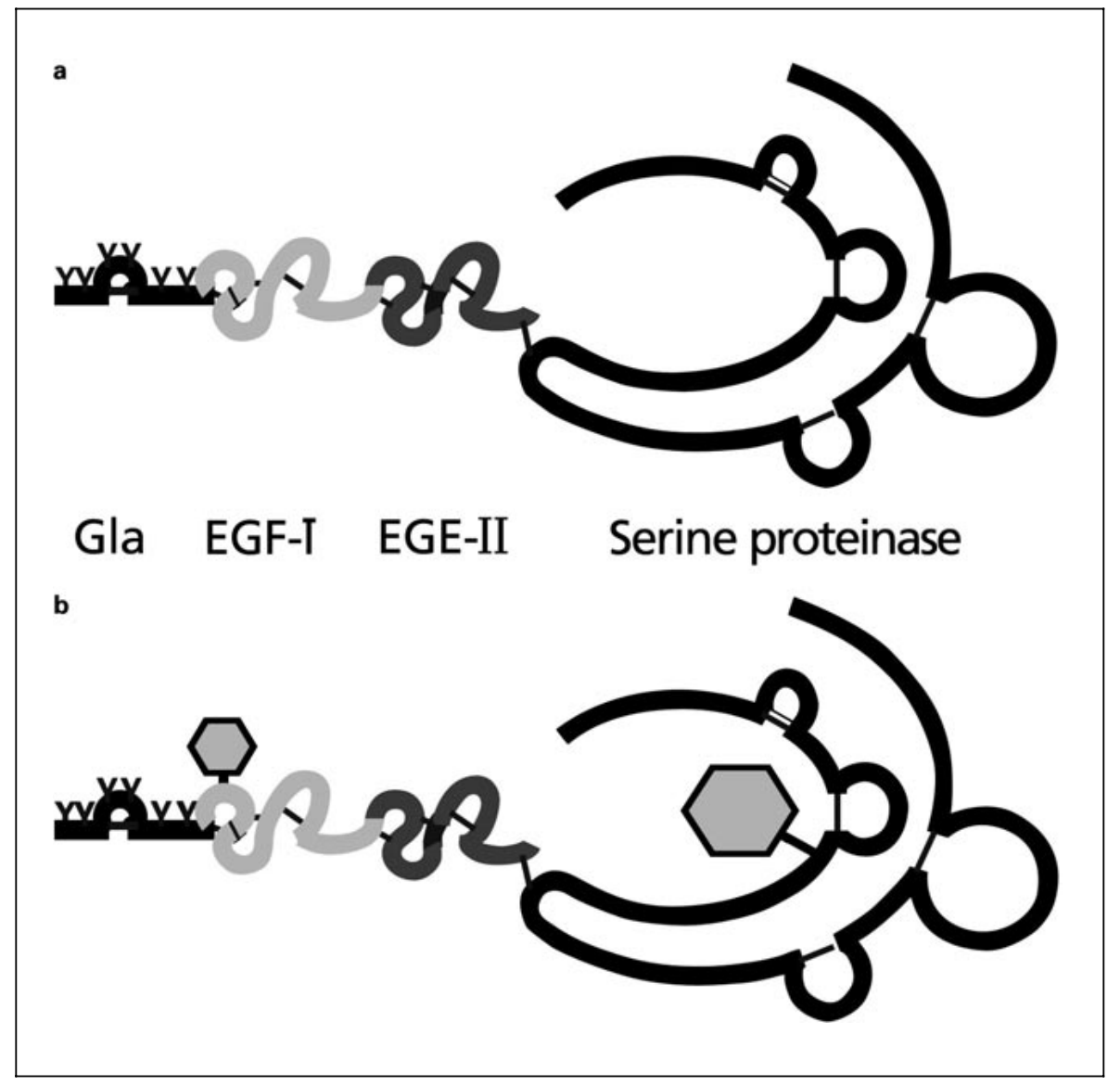

Fig. 2. Schematic representation of domain structure of factor $X a(\mathbf{a})$ and trocarin (b). Domains, disulfide linkages and post-translational modifications are depicted. $Y=\gamma$-Carboxylation; hexagons = carbohydrate moiety.

29 and 32 are critical for activity, while either one of the additional Glas in positions 35 and 39 could perhaps be dispensed with, without severely compromising activity [9]. Mass spectrometry and/or sugar compositional analysis indicated that trocarin is O-glycosylated at light chain Ser 52 (GlcNAc-Xyl or Gal-GalNAc) and N-glycosylated at heavy chain Asn 45 [9]. It is hence the first factor Xa-like protein known to be glycosylated. However, in factor VIIa, Ser 52 is glycosy- lated with disaccharide (-Glc-Xyl) or trisaccharide $\left[-G l c-(\mathrm{Xyl})_{2}\right]$ moieties $[14,15]$. Recombinant mutants in which Ser 52 was replaced by Ala had lowered ( 60\%) clotting activity, indicating that the glycosylation has significant functional implications [16, 17]. However, in trocarin the role of glycosylated Ser 52 is unknown. To the best of our knowledge, the GlcNAc-Xyl linkage has not been reported so far in proteins; it also represents the first known occurrence of O-linked 
GlcNAc in secreted proteins. Structural heterogeneity of the N-linked carbohydrate in trocarin precluded unequivocal assignment of its structure. Finally, unlike factor Xa, trocarin is not $\beta$-hydroxylated at light chain Asp 63 [9].

\section{Structural Comparison with Factor Xa}

Trocarin is highly homologous to other factors $\mathrm{Xa}(62-70 \%)$ [9] (see figure 1 for sequence comparison with human factor $\mathrm{Xa}$ ). By homology, it has a domain structure identical to factor Xa (fig. 2). Hence it is the first snake venom procoagulant that is structurally and functionally homologous to a blood coagulation factor. To complement 'linear' sequence analysis with three-dimensional perspective, we generated a molecular model of trocarin based on the human des-Gla factor Xa crystal structure, 1xka [18].

\section{Ca ${ }^{2+}$ Binding}

As mentioned above, the $\mathrm{Ca}^{2+}$-dependent membrane-binding Gla domain is well conserved in trocarin. The EGF-I domain of factor $\mathrm{Xa}$ is also involved in $\mathrm{Ca}^{2+}$ binding. In factor Xa, the side chains of Asp 63, Asp 46 and Gln 49 and the backbone carbonyl groups of Gly 47 and Gly 64 serve as $\mathrm{Ca}^{2+}$ ligands [19, 20] (fig. 1). All these residues are completely conserved in trocarin. Though Asp 63 is not modified in trocarin, it is unlikely to be involved in $\mathrm{Ca}^{2+}$ binding, as in factor $\mathrm{Xa}$, the $\beta$-hydroxyl group of hydroxyaspartate 63 points away from the metal ion [21, 22]. Another $\mathrm{Ca}^{2+}$-binding site is seen in the factor $\mathrm{Xa}$ crystal structure, bound in a loop defined by heavy chain residues 56-66 [18]. Interestingly, in trocarin, except for one residue (Asp 54 , conservative substitution), all of the other residues in this loop are not conserved (fig. 1). Loss of residues that are potential ligands for the $\mathrm{Ca}^{2+}$ ion (Asp 56, Asn 58, Thr 59, Gln 61, Glu 63 and/or Glu 66) seems to indicate loss of $\mathrm{Ca}^{2+}$-binding ability at this site in the heavy chain. Functional consequences of this are not yet known.

\section{Regions Important for Catalysis}

The heavy chain of trocarin is homologous to serine proteinases and the heavy chain of factor $\mathrm{Xa}$ and is evidently the catalytic subunit (fig. 1). All residues required for the specific catalytic activity of factor Xa are completely conserved: the active site catalytic triad (His 42, Asp 88 and Ser 185), the substrate-binding pocket (Asp 179, Ala 180, Cys 181, Gln 182) and residues involved in forming the hydrogen-bonded structure antiparallel to the substrate (Ser 204, Trp 205, Gly 206, Gly 216) [9]. The regions of factor Xa (heavy chain residues 81-93 and 221-231) found to be involved in the recognition of the substrate prothrombin [23] are also fairly well conserved in trocarin. However, as mentioned above, significant differences were observed in the ability of trocarin to hydrolyze factor Xa-specific peptide substrates. Examination of the vicinity of the active site in the model suggests a structural basis for this difference in activity. As mentioned, trocarin is N-glycosylated at heavy chain Asn 45 (only three residues removed from active site His 42). The $\mathrm{N}$-glycosylation $(\sim 3,300 \mathrm{D})$ is, intriguingly, positioned on the lip of the entrance to the active site. Hence it is possible that this large carbohydrate near the active site hinders the release of the hydrolysis products of synthetic peptide substrates, consequently affecting the Vmax of the reaction. 


\section{Regions Important for Interaction with Factor Va}

The EGF-II domain of trocarin is much less homologous to factor Xa [9] (fig. 1). The precise function of this domain in factor $\mathrm{Xa}$ is still not well understood. Domain-swapping experiments by Hertzberg et al. [24], involving factor IX Gla and EGF-I domains 'spliced' to factor X EGF-II and serine proteinase domains, indicated that the EGF-II domain may mediate factor Va binding, the affinity of which could be enhanced by the EGF-I domain [24]. If this domain is indeed involved in factor Va binding, its low homology in trocarin is especially intriguing, since trocarin binds strongly to bovine factor $\mathrm{Va}$ [unpubl. obs.]. Chattopadhyay et al. [23] also identified regions corresponding to heavychain residues $17-28$ and $60-82$ as being in important for interaction with factor Va. While, the segment from residues $17-28$ is quite conserved in trocarin, the heavy-chain residues $48-84$ in trocarin show surprisingly little similarity to the corresponding region of factor Xa (fig. 1). The consequences of this would be interesting to examine.

\section{Region Involved in Binding to Effector Cell Protease Receptor-1}

The inter-EGF domain region ${ }^{83}$ LFTK$\mathrm{RL}^{88}$ ) in factor $\mathrm{Xa}$, is implicated in interaction with its specific physiological receptor, effector cell protease receptor-1 (EPR-1) [25]. This interaction mediates inflammation [11], as well as mitogenesis in several cell types [26, 27]. Interestingly, this region is completely different in trocarin ${ }^{83} \mathrm{KVLYQS}^{88}$ ) (fig. 1). It is important to determine the functional consequences of these differences. We are currently investigating the ability of trocarin to induce inflammation and mitogenesis and the EPR-1 dependence of these effects, if any.

\section{Acknowledgement}

We acknowledge a National University of Singapore Academic Research Grants (R-154-000-093-112 and R-368-000-004-112) to RMK.

\section{References}

1 Suttie JW, Jackson CM: Prothrombin structure, activation and biosynthesis. Physiol Rev 1977;57:1-70.

2 Rosing J, Tans G: Inventory of exogenous prothrombin activators. Thromb Haemost 1991;65:627630 .

3 Markland FS Jr: Snake venoms. Drugs 1997;54(suppl 3):1-10.

4 Hutton RA, Warrell DA: Action of snake venom components on the haemostatic system. Blood Rev 1993; 7:176-189.
5 Kini RM, Morita T, Rosing J: Classification and nomenclature of prothrombin activators isolated from snake venoms. Thromb Haemost, in press.

6 Morita T, Iwanaga S, Suzuki T: Activation of bovine prothrombin by an activator isolated from Echis carinatus venom. Thromb Res 1976; 8(suppl 2):59-65.

7 Yamada D, Sekiya F, Morita T: Isolation and characterization of carinactivase, a novel prothrombin activator in Echis carinatus venom with a unique catalytic mechanism. J Biol Chem 1996;271:5200-5207.
8 Masci PP, Whitaker AN, de Jersey $\mathrm{J}$ : Purification and characterization of the prothrombin activator of the venom of Pseudonaja textiles; in Gopalakrishnakone $\mathrm{P}$, Tan CK (eds): Progress in Venom and Toxin Research. Proceedings of the First Asia-Pacific Congress on Animal, Plant and Microbial Toxins, Singapore 1987, pp 209-219.

9 Joseph JS, Chung MC, Jeyaseelan K, Kini RM: Amino acid sequence of trocarin, a prothrombin activator from Tropidechis carinatus venom: Its structural similarity to coagulation factor Xa. Blood 1999;94:621631. 
10 Tans G, Govers-Riemslag JWP, van Rihn JLML, Rosing J: Purification and properties of a prothrombin activator from the venom of Notechis scutatus scutatus. J Biol Chem 1985; 260:9366-9372.

11 Cirino G, Cicala C, Bucci M, Sorrentino L, Ambrosini G, DeDominicis G, Altieri DC: Factor Xa as an interface between coagulation and inflammation. Molecular mimicry of factor Xa association with effector cell protease receptor- 1 induces acute inflammation in vivo. $\mathrm{J}$ Clin Invest 1997;99:2446-2451.

12 Gasic GP, Arenas CP, Gasic TB, Gasic GJ: Coagulation factors X, $\mathrm{Xa}$, and protein $\mathrm{S}$ as potent mitogens of cultured aortic smooth muscle cells. Proc Natl Acad Sci USA 1992;89:2317-2320.

13 Ko FN, Yang YC, Huang SC, Ou JT: Coagulation factor Xa stimulates platelet-derived growth factor release and mitogenesis in cultured vascular smooth muscle cells of rat. J Clin Invest 1996;98:1493-1501.

14 Hase S, Kawabata S, Nishimura H, Takeya H, Sueyoshi T, Miyata T, Iwanaga S, Takao T, Shimonishi Y, Ikenaka T: A new trisaccharide sugar chain linked to a serine residue in bovine blood coagulation factors VII and IX. J Biochem 1988;104: 867-868.

15 Iwanaga S, Nishimura H, Kawabata S, Kisiel W, Hase S, Ikenaka T: A new trisaccharide sugar chain linked to a serine residue in the first EGFlike domain of clotting factors VII and IX and protein Z. Adv Exp Med Biol 1990;281:121-131.
16 Bjoern S, Foster DC, Thim L, Wiberg FC, Christensen M, Komiyama Y, Pederson AH, Kisiel W: Human plasma and recombinant factor VII. Characterization of O-glycosylations at serine residues 52 and 60 and effects of site directed mutagenesis at serine 52 to alanine. $\mathrm{J}$ Biol Chem 1991;266:11051-11057.

17 Iino M, Foster DC, Kisiel W: Functional consequences of mutations in Ser-52 and Ser-60 in human blood coagulation factor VII. Arch Biochem Biophys 1998;352:182-192.

18 Kamata K, Kawamoto H, Honma T, Iwama T, Kim SH: Structural basis for the chemical inhibition of human blood coagulation factor Xa. Proc Natl Acad Sci USA 1998;95: 6630-6635.

19 Stenflo J: Structure-function relationships of epidermal growth factor modules in vitamin K-dependent clotting factors. Blood 1991;78: 1637-1651

20 Selander-Sunnerhagen M, Ullner M, Persson E, Teleman O, Stenflo J, Drakenberg T: How an epidermal growth factor (EGF)-like domain binds calcium. High resolution NMR structure of the calcium form of the $\mathrm{NH}_{2}$-terminal EGF-like domain in coagulation factor $\mathrm{X}$. J Biol Chem 1992;267:19642-19649.

21 Valcarce C, Selander-Sunnerhagen M, Tamlitz A-M, Drakenberg T, Bjork I, Stenflo J: Calcium affinity of the $\mathrm{NH}_{2}$-terminal epidermal growth factor-like module of factor X. J Biol Chem 1993;268:2667326678.
22 Selander-Sunnerhagen M, Persson E, Dahlqvist I, Drakenberg T, Stenflo J, Mayhew M, Robin M, Handford P, Tilley JW, Campbell ID, Brownlee GG: The effect of aspartate hydroxylation on calcium binding to epidermal growth factor-like modules in coagulation factors IX and X. J Biol Chem 1993;268: 23339-23344.

23 Chattopadhyay A, James HL, Fair DS: Molecular recognition sites on factor Xa which participate in the prothrombinase complex. J Biol Chem 1992;267:12323-12329.

24 Hertzberg MS, Ben-Tal O, Furie B, Furie BC: Construction, expression, and characterization of a chimera of factor IX and factor X. The role of the second epidermal growth factor domain and serine protease domain in factor Va binding. J Biol Chem 1992;267:14759-14766.

25 Ambrosini G, Plescia J, Chu KC, High KA, Altieri DC: Activationdependent exposure of the interEGF sequence $\mathrm{Leu}^{83}-\mathrm{Leu}^{88}$ in factor $\mathrm{Xa}$ mediates ligand binding to effector cell protease receptor-1. J Biol Chem 1997;272:8340-8345.

26 Herbert JM, Bono F, Herault JP Avril C, Dol F, Mares AM, Schaeffer P: Effector protease receptor 1 mediates the mitogenic activity if factor Xa for vascular smooth muscle cells in vitro and in vivo. $\mathrm{J}$ Clin Invest 1998;10:993-1000.

27 Nicholson AC, Nachman RL, Altieri DC, Summers BD, Ruf, W, Edgington TS, Hajjar DP: Effector cell protease receptor-1 is a vascular receptor for coagulation factor Xa. J Biol Chem 1996;271:28407-28413. 